\title{
O SISTEMA ELEITORAL E A NECESSIDADE DE MUDANÇA
}

Lucas Ferreira Furlan, Sérgio Mastellini

Universidade do Oeste Paulista - UNOESTE, curso de Direito, Presidente Prudente, SP. Email: lucasfurlan94@hotmail.com

\section{RESUMO}

O presente artigo é um convite a uma análise clara e concisa do atual panorama políticoparlamentar brasileiro, tendo como principal objetivo demonstrar seus principais problemas e apontar possíveis caminhos para sua solução. De forma sucinta, debateremos a fragmentação das correntes políticas no país, a perda de força por parte do Congresso Nacional e dos Partidos Políticos; também tentaremos demonstrar como a substituição do sistema eleitoral-parlamentar poderá auxiliar na busca de uma solução para esses graves problemas. O sistema distrital, juntamente com o proporcional em dois turnos, serão analisados, com o intuito apontar como os mesmos podem aprimorar nosso debate e, acima de tudo, nossos resultados políticos.

Palavras-chave: Sistemas, Partidos, Parlamento, Representatividade e Eleições.

\section{THE ELECTORAL SYSTEM AND THE NEED FOR CHANGE}

\begin{abstract}
This article calls for a clear and concise analysis of current Brazilian parliamentary political landscape, with the main objective to demonstrate its main problems and point out possible paths to for your solution. Briefly we will discuss the fragmentation of political currents in the country, the loss of power by the National Congress and the Political Parties and attempt to demonstrate how the replacement of the parliamentary electoral system can assist in the search for a solution of these serious problems, the district system well as the proportion of two shifts will be analyzed in order to point out how these can improve our debate and above all our political results.
\end{abstract}

Keywords: Systems, Parties, Parliament Representation and Elections. 
INTRODUÇÃO

Há cerca de dois anos, o Brasil vem debatendo a elaboração de sua tão esperada reforma política. Neste trabalho, teremos, como objetivo principal, o debate sobre os problemas que a política nacional enfrenta, tais como a total falta de agenda por parte dos partidos políticos e a degradação da força do Congresso Nacional perante a sociedade.

O presente artigo objetiva demonstrar como a alteração do sistema eleitoral, para as eleições parlamentares, poderá solucionar a terrível crise de representatividade na qual nos encontramos. De forma concisa, analisaremos as possíveis adoções tanto do sistema distrital quanto do proporcional em dois turnos.

\section{METODOLOGIA}

O artigo foi norteado por pesquisas bibliográficas, leituras e fichamentos. Os dados foram analisados com emprego do método hipotético-dedutivo, informações coletadas analisadas e confrontadas de forma dialética.

\section{RESULTADOS}

Os resultados alcançados com a presente pesquisa foram concretos, de forma a contribuir com o debate político nacional, no sentido de demonstrar a necessidade de mudança do sistema eleitoral-parlamentar.

\section{DISCUSSÃO}

\section{O Pluripartidarismo e as Legendas de Aluguel}

Durante o período de abertura democrática ocorrido após a Ditadura Militar, a maioria das lideranças políticas optou pelo sistema pluripartidário, em face do sistema bipartidário, que vigorou durante grande parte desse regime. Com isto, o pluripartidarismo prevaleceu e vigora até os dias atuais, sendo garantido, inclusive, como clausula pétrea da Constituição da República.

Segundo DUVERGER (apud Dallari, 2013, p. 166), o pluripartidarismo tem duas causas principais, sendo uma delas o fracionamento de correntes de opinião. Agora vejamos que o Brasil possui atualmente, 32 partidos políticos, sendo que outras seis agremiações já estão em fase adiantada, para conseguir obter o registro junto ao TSE, chegando, então, a um total de 38 legendas. Diante disto, façamos as seguintes perguntas, existem hoje, em nossa República, 38 linhas de pensamento político? ; O eleitor tem, à sua disposição, durante o pleito eleitoral, 38 caminhos pelos quais optar? A resposta só pode ser negativa. 
Se formos analisar a fundo, desde a redemocratização, salvo a eleição de 1989 , em todos os demais pleitos presidenciais, o eleitor só possuía dois caminhos viáveis, representados, sempre, pelos candidatos do PT (Partido dos Trabalhadores) e do PSDB (Partido da Social Democracia Brasileira). Destarte, todas as demais legendas, comportadas as exceções, ficam gravitando ao redor dos dois gigantes da política, sendo que, curiosamente, a maioria delas opta por aquele que está no poder.

Durante o período que compreende de 1994 a 2002, a base de sustentação do Governo, no Congresso, era composta principalmente por três partidos: o PSDB, partido do então presidente Fernando Henrique Cardoso; o PFL, partido do vice-presidente Marco Maciel; e o PMDB. Isto, por que, nesse tempo, eles eram os gigantes da política nacional; juntos somavam quase 300 deputados. Porém, com a intensificação da troca de cargos por apoio político, comandar legendas partidárias se tornou algo muito vantajoso para seus dirigentes.

Dessa forma, muitos políticos migraram de seus respectivos partidos para outros, inflando, com isto, as bancadas dos partidos menores. Outros, no entanto, preferiram fundar o seu próprio partido, alguns saindo, inclusive, da oposição e indo para a situação, tentados, quem sabe, por alguma vantagem pessoal.

Em sua obra, Reforma Política o Debate Inadiável; o Cientista Político Murillo de Aragão descreve, com exatidão, a situação atual (2014, p.70):

Inicialmente, deve-se destacar que controlar um partido é um bom negócio, porque insere seu dono na roda das fortunas da política de verbas e cargos. Por isso, quem tem, não abre mão. É uma espécie de cartório com dois grandes poderes: o de dar vagas a quem concorre e o de ceder seus espaços gratuitos na TV para blocos políticos maiores. Tudo sustentado pelo dinheiro público.

Hoje, a base governista é composta por dez legendas, que dividem, entre si, trinta e nove ministérios, milhares de cargos comissionados e as diretorias das empresas estatais. Prova cabal de que se trata de uma base "alugada", como dizem alguns jornalistas, é fato de que os mesmo partidos que montam a base do Governo petista, no plano nacional, também estão presentes na base governista das Assembléias Legislativas dos estados governados pela oposição.

Esse modo de fazer política levou o Brasil a ter apenas duas grandes correntes políticas, a dos petistas e seu aliado histórico, o PC do B; e a dos tucanos e juntamente com seu histórico aliado, o DEM (antigo PFL); o PMDB, maior partido do Brasil, é, sem duvida, o grande exemplo dessa prática inadequada da política nacional. Basta-nos lembrar a história. 
Nas eleições de 2002, quando os tucanos estavam no Governo, o candidato governista à presidência foi o então Ministro da Saúde, José Serra. Sua candidata a vice presidente foi a deputada capixaba Rita Camata, do PMDB. Já nas eleições presidenciais de 2010, com os petistas no comando da República, a candidata ao Planalto foi a então ministra da Casa Civil, Dilma Rousseff; e o candidato a vice-presidente foi o deputado paulista Michel Temer, também do PMDB. Comportadas algumas exceções regionais, O PMDB sempre está com o Governo, independente de qual seja, pois o partido não lança um candidato à Presidência da República desde as eleições de 1989.

Outros exemplos regionais merecem destaque; nas eleições de 2014, os governadores tucanos, Geraldo Alckmin, em São Paulo, e Beto Richa, no Paraná buscavam a reeleição. Seus principais adversários foram candidatos do PMDB. Passada a eleição, tendo sido os governadores reeleitos, o PMDB imediatamente adentrou a base de apoio dos governadores em suas respectivas Assembléias Legislativas, meio adotado por outra dezena de partidos em nosso país.

Esta prática pôde por algum tempo, ser combatida pela aplicação do princípio da coerência na formação de coligações, criado pelo TSE e aplicado nas eleições presidenciais de 2002 e 2006. Este princípio proibia que o partido que apoiasse ou lançasse candidato à Presidência da República, apoiasse em plano estadual um partido que tivesse lançado candidato próprio a presidência ou estive-se em coligação adversária.

Todavia, em 2006, o Congresso Nacional, com claro fim de burlar a aplicação deste princípio, promulgou a Emenda Constitucional $\mathrm{n}^{\circ}$ 52, que expressamente prevê, como componente de autonomia dos Partidos Políticos, a possibilidade de estes escolherem qual candidatura apoiar em âmbito nacional, estadual, distrital ou municipal, sem qualquer tipo de regulamentação.

A sanha política pelo fim da aplicação deste princípio era tanta, que o texto da Emenda chegou ao disparate de expressamente prever que ela já teria aplicabilidade para as eleições daquele ano, afrontando a norma Constitucional, que prevê que a lei que altera o processo eleitoral só terá valor nas eleições que ocorrerem um ano após a sua entrada em vigência. Diante disto o STF se posicionou, determinando a inaplicabilidade do texto da $E C n^{\circ} 52$ para as eleições de 2006. Nas eleições presidenciais de 2010, o "show" dos horrores retornou.

Fatos, como estes, só vêm demonstrar, de forma explícita, o total desinteresse da classe política para com país, com uma preocupação contínua com manter negociatas obscuras e, acima de tudo com sua perpetuação no poder, colocando, sempre, o interesse individual à frente do 
coletivo, contribuindo, para que grande parte da população passe a sentir desinteresse pela política e abandone o debate, por não se sentir representada por aqueles que os governam.

\section{O Enfraquecimento dos Partidos e do Congresso}

Sem dúvida alguma, o caminho, para se obter uma República forte, passa, necessariamente, pela existência de partidos políticos fortes e, consequentemente, de um Congresso forte. Porém, nos últimos anos, testemunhamos o enfraquecimento tanto dos partidos políticos quanto do Congresso Nacional.

Devido à adoção das práticas já debatidas acima, os partidos deixaram de possuir uma ideologia e passaram a ficar dependentes dos nomes de seus políticos, para obter vitórias. Hoje, a grande maioria da população, ao votar, não analisa o partido em si, mas sim, o político no qual ela está votando. Justamente por isto, a troca de partidos se tornou uma prática corriqueira.

O Congresso Nacional foi, também, duramente afetado por este sistema, já que, como a imensa maioria dos partidos que compõem o parlamento são dependentes da máquina publica, o Executivo acabou conseguindo impor sua pauta ao Congresso, fazendo com que somente projetos de seu interesse fossem analisados e votados.

Uma simples análise externa mostra que as grandes democracias mundiais só chegaram a este patamar, com a existência da equação: partidos políticos e parlamento forte. Entretanto, o atual sistema eleitoral existente no Brasil dificilmente permitirá que isto ocorra, gerando a necessidade de se reformar o sistema eleitoral.

\section{A Reforma Política e a Necessidade de Mudança}

O Sistema eleitoral nada mais é do que a forma como os eleitores escolhem seus representantes, devendo estar sempre adequado com as peculiaridades do eleitorado, bem como com as necessidades do período que o país enfrenta.

No sistema atual, utilizado pelo Brasil desde as eleições de 1945, a eleição dos Representantes do Poder Legislativo, com exceção dos senadores, é o proporcional, que funciona da seguinte forma: o número de votos válidos destinados ao legislativo é dividido pelo número de cadeiras disponíveis no parlamento, formando-se o coeficiente eleitoral. Após isto alcançasse o coeficiente partidário, que é o resultado da divisão do número de votos conferidos à legenda ou coligação pelo coeficiente eleitoral, o resultado desse cálculo determinará a quantidade de vagas amealhadas pelo partido dentro do parlamento, assumindo-as os candidatos que obtiverem as maiores votações dentro da sigla. 
Sem dúvida alguma, o sistema atual cumpriu seu papel ao longo da história, mas, nos últimos tempos, tem-se mostrado ineficaz, para combater os novos problemas que a política nacional enfrenta. Desse modo, dentre os novos sistema que estão sendo debatidos como prováveis sucessores do sistema atual, podemos destacar dois, sendo eles o Distrital ou Distrital Misto e o Proporcional de Dois Turnos.

Iniciaremos pelo distrital, por cujo sistema o colégio eleitoral é dividido pelo número de vagas em disputa para o legislativo, formando-se, dessa forma os distritos, podendo cada sigla lançar um candidato em cada distrito, sendo a eleição feita pelo sistema majoritário, vencendo, desse modo, os candidatos que obtiverem as maiores votações.

O sistema distrital foi implantado de forma variada, ao redor do globo, sempre com o intuito de sanar algumas falhas existentes. Desta feita, as criticas mais recorrentes ao sistema são as de que as minorias sentem dificuldade em alcançar representatividade, e que corriqueiramente, como existe uma grande quantidade de candidatos por distrito, o que é eleito possui uma votação muito aquém da maioria de eleitores da localidade.

Para tentar corrigir esses problemas, alguns Estados implantaram o sistema distrital misto, onde parte das cadeiras é preenchida pela eleição majoritária no distrito e a outra parte pela eleição proporcional, que pode ser feita somente no distrito ou em todo o colégio eleitoral. No que diz respeito ao segundo problema, foi implantado, em diversos lugares, o sistema de dois turnos, como já é feito no Brasil, nas eleições para cargos do executivo.

Atualmente, a implantação do Sistema Distrital tem sido defendida pelo PSDB, tendo também o PMDB defendido a implantação do chamado "Distritão", que consiste na transformação de cada estado em um único distrito eleitoral, sendo, dessa forma, eleitos os candidatos mais votados de cada estado. Ou seja, na prática seria adotado o sistema majoritário puro e simples.

A implantação do Sistema Distrital terá como grande vantagem, a aproximação do eleitor do eleito, já que a cada parlamentar incumbirá, como encargo, a representação de uma determina região de seu estado. Outra grande vantagem do referido sistema é a grande margem de ajuste que este permite, dada a existência das possibilidades de sua implantação, tanto no sistema misto quanto no de dois turnos. Ambas as possibilidades serão muito acertadas em nosso país, em razão de possibilitarem um debate mais aprofundado por parte da população nas eleições parlamentares, visto, que, hoje este praticamente inexiste.

A respeito do Sistema Distrital leciona Dalmo de Abreu Dallari em sua obra, (DALLARI, 2013) 
Entre outras coisas, o representante poderá concentrar os seus esforços sobre um menor número de problemas, uma vez que deverá dar maior ênfase ao trabalho em favor de seu respectivo colégio eleitoral. E isto, obviamente, sem deixar de ter participação nos assuntos de interesse geral do Estado, sobre os quais conhecerá melhor o pensamento de seus eleitores, podendo então agir como verdadeiro representante. O próprio eleitorado do distrito, sabendo quem efetivamente o representa, terá interesse em aumentar a eficiência da representação, oferecendo subsídios e sugestões que permitam a elaboração de proposições.

É adequado reparar que os ensinamentos do nobre jurista não só vêm complementar o que já havia sido dito a respeito da maior representatividade do eleitor por parte do eleito mas também confronta uma corriqueira crítica ao Sistema, mediante a qual os parlamentares passariam a se descuidar do temas de interesse nacional, por terem de se dedicar, integralmente, aos Distritos. Com isto, damos por encerrada, a analise do referido sistema e passaremos ao proporcional em dois turnos.

Como já dito acima, a construção de uma República forte passará, necessariamente por partidos políticos fortes, um sistema que, sem dúvidas, tem, como fundamento, o fortalecimento das legendas partidárias e o proporcional de dois turnos.

O sistema funciona da seguinte forma: em um primeiro turno, o eleitor vota diretamente no número da legenda partidária, utilizando-se do método do sistema proporcional comum, mediante o qual é alcançado o número de cadeiras que cada partido conseguiu obter no parlamento. Dessa forma, no segundo turno, o eleitor irá votar em um candidato da sigla, para preencher as cadeiras por ela conquistadas. Por exemplo, em um primeiro turno, o partido " $A$ " alcançou votos suficientes, para lhe dar direito a 10 cadeiras no legislativo. No segundo turno, portanto, o partido apresentara seus candidatos para estas vagas, a fim de que o leitor escolha, dentre os nomes apresentados pela legenda, quais assumirão o cargo.

Pela proposta hoje apresentada pelos defensores do sistema no segundo turno, o partido poderá lançar até o dobro de candidatos, referentes ao número de cadeiras que conseguiu amealhar no primeiro turno. Fica clara que, com a adoção desse sistema, os partidos terão, como obrigação, de se comprometer com uma pauta representativa e adequada às demandas da sociedade, para que, assim, consigam adquirir a preferência do eleitor. Ou seja, só os que adotarem uma agenda positiva conseguirão sobreviver na política.

Vale destacar-se que a implantação desse sistema só conseguirá, de fat, cumprir o seu papel de fortalecer os partidos se, com ele for determinado o fim das coligações eleitorais para o 
legislativo, ou, caso estas permaneçam, for aplicado, novamente, o princípio da coerência na formação destas.

\section{CONCLUSÃO}

Tendo chegado ao fim de nosso estudo, constatamos ter alcançado o objetivo inicial de apontar como o sistema político-parlamentar se degradou nos últimos anos e, portanto, as mudanças se fazem urgentes, sendo evidente que uma grande democracia só será erguida, quando nossos políticos forem, de fato, compromissados com uma agenda voltada para a nação, e não para seus próprios interesses.

Acreditamos que os problemas aqui apresentados podem ser facilmente solucionados, se, com o tempo, o país promover a substituição do sistema proporcional simples, tanto pelo distrital quanto pelo proporcional de dois turnos, sistemas que visam ao favorecimento dos verdadeiros estadistas e dificultam a articulação de manobras e barganhas, para favorecer este ou aquele grupo, posto que as grandes democracias mundiais só conseguiram chegar ao patamar em que se encontram, por possuírem concomitantemente, partidos políticos e um parlamento forte, ambos comprometidos com uma pauta em favor da coletividade, razão por que o Brasil, portanto deve trilhar por este mesmo caminho.

\section{REFERÊNCIAS}

ARAGÃO, M. A reforma política o debate inadiável. 1. ed. Rio de Janeiro: Civilização Brasileira, 2014.

CAPEZ, F. Sistemas Políticos. In: CAPEZ, F. Direito constitucional simplificado. São Paulo: Saraiva. 2013. P. $140-147$.

DALLARI, D. A. Sistemas Eleitorais. In: DALLARI, D. A. Elementos da teoria geral do estado. São Paulo: Saraiva. 2013. P. 190-197.

NOVELINO. M. Sistemas Eleitorais. In: NOVELINO. M. Manual de direito constitucional. Rio de Janeiro: Gen. Método. 2013. P. 679-691.

PINTO, C.C. Sistema Eleitoral Majoritário e Sistema Proporcional. In: PINTO, C .C. Curso de teoria geral do estado. São Paulo: Atlas. 2013. P. 202-204.

FURLAN, F, L. A reforma política e o voto distrital. Colloquium humanarum, Presidente Prudente, vol.11,n. especial, mês. jul/dez, 2014. Disponível em: $\leq$

http://www.unoeste.br/site/enepe/2014/suplementos/area/Humanarum/Direito/A\%20REFORMA\%20POL\%C3\%8DTI CA\%20E\%200\%20VOTO\%20DISTRITAL.pdf z. Acesso em: 20 jun. 2015. 